\title{
Adolescentes con episodios conflictivos con la ley penal: Restituir derechos y construir ciudadanía. Reflexiones \\ a partir del Programa Propiciar de La Matanza.
}

Youngsters in conflict with criminal law: giving back rights and building citizenship. The "Propiciar Program" in the Municiality of La Matanza

Javier Moro

Investigador del área de política social del Instituto del Conurban de la Universidad Nacional

de General Sarmiento.

moro@,ungs.edu.an

Guillermo Orizaol

ion dis Director de Coon hación del sistena

gorizaola@gmail.con

Fecha de recepción:

13.3.17

Fecha de aceptación

25.4.17

\section{Resumen}

Este artículo propone algunas reflexiones en torno a las posibilidades de intervenir en problemáticas complejas a través de políticas sociales con enfoque de derechos desde un municipio del conurbano bonaerense. En un contexto donde algunos actores promueven la baja de la edad de punibilidad a partir del estereotipo de los jóvenes de sectores popuares como peligrosos, nos parece relevante y oporno analizar la gestión del Programa Propicia en La Matanza con adolescentes no punibles. Allí destacamos: la (re)definición del problema para no continuar un sentido punitivo en la intervención la propuesta de un abordaje territorial basado en derechos; algunas tensiones en la implementación; los alcances y límites vinculados a las particularidades de territorios signados por la desigualdad y la exclusión y al déficit de políticas públicas de mayor escala; finalmente, se argumenta que este tipo de bordajes pueden resultar una referencia con respecto a qué se puede y se debe hacer en materia de políticas sociale 
Palabras clave: políticas sociales - derechos adolescentes - ley penal - territorio - La Matanza

\section{Abstract}

Some of the complexities of municipal policy interventions with regard to youngsters conflicting with criminal law are discussed in this article. Amidst intense arguments for and against a crass punitive approach, a proposal is conducted here towards a policy approach paying attention to the specificities of socioterritorial settings such as inequality or social exclusion, as well the effective enforcement of human rights. The discussion on the outreach and limits of different policy proposals is conducted through a case study of "ProgramaPropiciar" implemente in the Buenos Aires Province Municipality of La Matanza.

Key-words: social policies - rights - youngsters - criminal law-territory - La Matanza

\section{Presentación}

Una vez más los adolescentes y jóvenes emergen en la agenda pública ligados al tema de la (in)seguridad desde discursos que instalan la idea de peligrosidad de los mismos y sustentan la necesidad de "mano dura" como mejor o única fórmula en pos de la defensa del resto de la sociedad.En esta ocasión vuelven a poner el eje del debate en la baja de la edad de punibilidad (actualmente establecida en 16 años). ${ }^{1}$ A esto se agrega el particularismo regional del área metropolitana, donde el conurbano bonaerense, signado por la desigualdad y con amplias zonas de segregación, se presenta como un territorio casi inexpugnable para(de)mostrar efectividad de las políticas sociales que se enmarquen desde abordajes más integrales (y por ende, complejos) y pretendan ser coherentes con un enfoque de derechos. ${ }^{2} \mathrm{Al}$ respecto, la ley nacional 26061 del año 2005 adecuó la normativa interna a los principios establecidos en la Convención Internacional sobre Derechos del Niño. ${ }^{3}$

En una coyuntura donde el cruce de imágenes de varones jóvenes y conurbano potencia estereotipos de peligrosidad muy afines a la lógica mediática punitiva (Salgado 2015), nos parece oportuno retomaralgunas reflexiones sobre un programa gubernamental del municipio de La Matanza (Propiciar) en torno a los adolescentes no punibles que tuvieron algún conflicto con la ley penal y que ya lleva ocho años de implementación. ${ }^{4}$
Para ello primero realizamos una breve descripción del actual contexto institucional a nivel provincial (apartado 1) más algunas características sociodemográficas del municipio (apartado 2) y una sinapsis del sistema de protección y promoción de derechos a escala local (apartado 3).Luego revisamos el ingreso del problema en la agenda municipal (apartado 4) donde destacamos la capacidad de los actores locales para (re)definir el problema en cuestión (en términos de vulneración de derechos y no continuar un sentido punitivo en la intervención) y se analiza el encuadre conceptual del Propiciar. Posteriormente, se pone el foco sobre el proceso de implementación considerando particularmente los nudos críticos y las tensiones programáticas que se plantean (apartado 5) a la par que también ponderamos los alcances y límites de la intervención vinculados a las características de territorios signados por la desigualdad y la exclusión y al déficit de políticas públicas de mayor escala que traccionen positivamente la estructura de oportunidades de las familias y faciliten procesos de integración urbana. Finalmente (apartado 6) en una coyuntura en que se promueve la baja de la edad de imputabilidad ${ }^{5}$ se argumenta que este tipo de abordajes pueden resultar una referencia con respecto a qué se puede y se debe hacer desde el Estado en materia de políticas sociales, antes que pugnar por las acciones punitivas (como la baja de edad de punibilidad)

La restitución de derechos es un deber inalienable del Estado que atañe a sus tres poderes (ejecutivo, legislativo y judicial) y a sus tres niveles jurisdiccionales (nación, provincia y municipios). Pero, además de una cuestión normativa (legal y ética) consideramos que, en situaciones de exclusión, la acción estatal a través de políticas activas de expansión de derechos resulta una condición necesaria para posibilitar la construcción de ciudadanía. Esto refiere a un proceso -desde ya complejo- que implica el reconocimiento de sujetos con derechos y responsabilidades, interpelados desde una autoridad legítimamente reconocida por los propios involucrados; lo que supone un Estado que se hace presente principalmente por los servicios sociales básicos, por la infraestructura urbana y por promover políticas de creación de empleo e inclusión social que mejoren las condiciones de vida de las familias y comunidades más postergadas.

En el plano metodológico cabe consignar que el análisis del Programa Propiciar forma parte de la investigación "La construcción de una nueva institucionalidad pública a nivel local: las áreas de niñez y adolescencia en el conurbano bonaerense". ${ }^{6}$ En este marco, el análisis que aquí se desarrolla se apoya en información generada a través de la revisión de fuentes secundarias -tales como la normativa, documentos oficiales y registros estadísticos-, así como también en información cualitativa obtenida a través de entrevistas abiertas como también mediante charlas informales que, en muchos casos, devinieron entrevistas espontáneas con informantes claves involucrados en la gestión local del sistema de protección y promoción de derechos de niños/as y adolescentes de La Matanza -sostenidas en diferentes instancias de intercambio y espacios de observación a lo largo del período analizado (2009-2015)-. La triangulación de las distintas fuentes nos permi- 
te poner en tensión el plano normativo y del diseño programático e institucional con el plano de la implementación. Entendido este último como un proceso donde a través de prácticas y procedimientos (con un grado de estandarización variable y un margen de autonomía y de discrecionalidad implícitos) se dirime la interacción de la llamada 'burocracia a nivel de calle' entre sí (con sus respectivas adscripciones a diferentes áreas sectoriales y niveles jurisdiccionales) y con la población destinataria (los adolescentes, sus familias y referentes territoriales). Es en ese espacio de interacción cara a cara, que en esta temática remite a una lógica de intervención que se ajusta a cada intervención (o caso), es donde se dirimen las acciones sociales del Estado local y el sentido de las mismas con respecto a los adolescentes no punibles que tuvieron episodios de conflicto con la ley penal.

\section{Un contexto de cambio institucional en la Provincia}

La Provincia de Buenos Aires lleva una década de un proceso de cambio institucional en el área de las políticas sociales dirigidas a la infancia y la adolescencia en situación de vulnerabilidad, a partir de la modificación del marco normativo que derogó el sistema de minoridad y creó el Sistema de Promoción y Protección Integral de los Derechos del Niño con incidencias en el plano judicial y en el administrativo. Este nuevo marco normativo está conformado por la ley 13298 -modificatoria14537- (con su decreto reglamentario $\left.\mathrm{N}^{\circ} 300 / 05\right)$ y la ley 13634 -modificatoria 13645 -. Si bien la ley 13.298 data de 2005, no pudo ser implementada sino hasta 2007 debido a una medida cautelar interpuesta por parte de la procuradora provincial. ${ }^{7}$ Finalmente, el nuevo Sistema de Protección Integral entró en vigencia en abril de 2007 con la decisión de la Corte Suprema que falló a favor de su implementación. ${ }^{8}$

Acá resaltaremos algunos aspectos de este cuerpo normativo que nos interesan para el presente trabajo. Como punto de partida vale destacar que esta nueva normativa busca una adecuación a la Convención Internacional de los Derechos del Niño, donde el reconocimiento del niño/a y adolescente como sujetos de derechos se postula como un pilar de la nueva institucionalidad e implica un cambio radical respecto al sistema tutelar. La ley 13.298 deroga el régimen tutelar de minoridad, explicita la competencia del ejecutivo en asuntos derivados de causas sociales para evitar su judicialización y restringe taxativamente la internación ante situaciones asistenciales, a su vez crea en los ámbitos ejecutivos municipales a los Servicios Locales de Promoción y Protección de Derechos (art. 18 de la ley 13298,que coloca en un rol hasta entonces inédito a los municipios) y a los Servicios Zonales como instancias desconcentradas del Ministerio a nivel regional (decreto reglamentario 300). ${ }^{9}$

En este punto vale un señalamiento, si bien la ley crea los servicios locales, lo plantea a través de un convenio de adhesión entre los municipios y el gobierno provincial repre- sentado en ese momento por el Ministerio de Desarrollo Social (si bien desde diciembre de 2011 la Secretaría de Niñez y Adolescencia adquirió rango ministerial, en 2016 lo perdió al ser absorbida por el Ministerio de Desarrollo Social, conformándose ahora en el Organismo Provincial de la Niñez y Adolescencia), lo que en la práctica se tradujo en un escenario bastante heterogéneo donde al día de la fecha no están adheridos la totalidad de los municipios. Esto se vincula también a que la ley, si bien planteaba una nueva arquitectura institucional no contó con recursos adicionales para solventarla sino que se utilizó el fondo de programas sociales preexistente (más adelante se profundiza este aspecto).

En el nuevo marco legal, las funciones que antes ejercían los Jueces de Menores fueron absorbidas por el Fuero de la Responsabilidad Penal Juvenil, el Fuero de Familias y los Sistemas de Promoción y Protección de Derechos provinciales y municipales. En el Fuero de la Responsabilidad Penal Juvenil (ley 13634), se crearon los Juzgados de Garantías del Joven, cuya función sería la de velar por el cumplimiento del debido proceso; las Fiscalías del Fuero, como parte acusatoria; las Unidades de Defensa del Joven -en reemplazo de los Asesores de Menores en el ejercicio de la defensa, quienes quedaron como representantes legales de los niños en los casos en que no los tuvieran los Juzgados y Tribunales de la Responsabilidad Penal Juvenil, como instancias de juicio; y las Cámaras de Apelación y Garantías en lo Penal, como instancias de revisión. En el marco del poder ejecutivo, se crearon los Centros de Referencia del Joven -dependientes del gobierno provincial- como órganos de cumplimiento de medidas alternativas a la privación de la libertad. También dentro de la esfera del gobierno provincial, se crearon centros de alojamiento especializados para jóvenes privados de la libertad.

De este modo, se incorporan las garantías del debido proceso para los mayores de 16 años sospechados de infringir la ley penal. Se instituyen los juzgados de garantías del joven a cargo de la investigación procesal penal y los juzgados de responsabilidad penal juvenil a cargo del juzgamiento. Este proceso anteriormente estaba en manos del Juez de Menores (decreto ley 10067 de 1983)quien tenía competencia para tomar decisiones tanto en situaciones de índole penal como cualquier temática que afectara el desarrollo de la niñez o, dicho en los términos de esa perspectiva, de menores en situación irregular (situación de abandono, deserción escolar, abuso sexual, situación de calle, conflicto con la ley penal, adicciones, violencia, etc.) (Beloff 1999).

La ley 13634 ha sido reconocida por incorporar las garantías constitucionales y del derecho internacional; sin embargo también ha recibido críticas (por ejemplo Vitale y Ábalos 2007), particularmente respecto a que el capítuloVI “de los niños inimputables" deja a criterio del juez la aplicación de medidas judiciales a los menores de 16 años "indicados' de haber cometido un delito.Esto abarca tanto medidas de protección (art. 63) como medidas restrictivas de libertad (art. 64)..$^{10}$. Este 'resquicio' de la ley ha recibido un cuestionamiento por parte de la Cámara Nacional Criminal y Correccional Federal que 
dictaminó:"Pese a la inimputabilidad de menores de 16 años se habilita a los jueces de menores a intervenir discrecionalmente, adoptando medidas intromisivas... se desprende de allí que la inimputabilidad declarada no implica per se un renunciamiento a la intervención penal coactiva, ya que, aun en ese caso, el niño es susceptible de la injerencia estatal, a través de la aplicación de medidas tutelares..." (Vitale y Abalos, 2007: 16). Estos autores también plantean que los adolescentes no punibles en conflicto con la ley penal (en ocasiones) encuentran una nueva instancia de intervención en los Servicios Locales de Promoción y Protección de Derechos. ${ }^{11} \mathrm{Al}$ respecto, vale señalar que, como ya se mencionó, los Servicios Locales dependen de los gobiernos municipales y se incorporan al Sistema a través de un convenio de adhesión; esto, más una rutina oganizacional en la que los actores provinciales suelen tener poca impronta (tal como se desarrolla más adelante)otorga a estos nuevos organismos un margen de autonomía considerable respecto de los Servicios Zonales y del propio Ministerio/Secretaría u Organismo Provincial. Por tanto, la articulación entre el poder judicial y el gobierno local bien puede quedar muy reducida o construirse de manera significativa según la decisión política y capacidad de gestión del municipio. A la vez, la continuidad de una acción punitiva (más o menos velada a través de intervenciones sociales) o su reorientación a través de acciones efectivas de restitución de derechos quedan abiertas a la capacidad de los actores del nivel local (este punto se profundiza en el análisis del Propiciar). ${ }^{12}$

\section{Una breve caracterización del municipio de La Matanza}

El municipio de La Matanza es el más grande del conurbano bonaerense. Posee una extensión territorial de $325,71 \mathrm{~km} 2$ y una población de 1.873 .123 personas, según datos de la Encuesta de Condiciones de Vida de La Matanza del año 2012 (en adelante ECVLM, 2012). Está integrado por 15 localidades y presenta fuertes heterogeneidades hacia su interior. A los fines analíticos suele agruparse a las localidades en tres áreas: la primera, lindante a la Ciudad Autónoma de Buenos Aires, va desde General Paz hasta el camino de Cintura (de mayores ingresos); la segunda, integrada por las localidades de Gregorio de Laferrére, Isidro Casanova, Ciudad Evita y Rafael Castillo (de ingresos medios); y la tercera, por las localidades de G. Catan,Virrey el Pino y 20 de Junio (ingresos bajos). El $32 \%$ de los matanceros reside en el área uno, otro 25\% en la dos y el núcleo más numeroso, con el 43\%, en el área tres.

Del total de la población del distrito, 636.000 son niños/as y adolescentes menores de 18 años, que habitan en el 58\% (313.000) de los hogares del municipio. En el área 3, el 73\% de los hogares tiene al menos un niño/a o adolescente, mientras que en la 1 , esa cifra es de 42,5. En el año 2012, el 15,6\% de los menores de 18 años se encontraba en situación de pobreza, lo que en ese momento refería a cerca de 100.000 niños/as y adolescentes pobres, que a su vez se concentran mayoritariamente en el área 3 (ECVLM, 2012). ${ }^{13}$
En términos de necesidades básicas, la citada encuesta muestra que el 62\% de los menores de 18 años no tiene cobertura de salud por plan médico u obra social, lo que equivale a 440.000 niños y adolescentes. El 59\% de los niños que no tienen cobertura de salud, se encuentra en la zona 3.El 65\% de los niños de menos de 18 años vive en hogares que no tienen acceso a servicios de cloacas. El $77 \%$ de los niños que no tiene acceso a servicios de cloaca y el $66 \%$ de los que no tienen acceso a agua potable se encuentran en la zona 3. El 22\% de los menores del distrito vive en hogares que se encuentran hacinados. El 65\% de los niños que viven en situación de hacinamiento residen en la zona 3.

En síntesis, se trata de un municipio bastante típico de las periferias urbanas en la Argentina, atravesado por problemáticas complejas de pobreza, salud y acceso a servicios (agravadas en este caso por sus dimensiones y cantidad de población).

\section{La construcción de la nueva institucionalidad a nivel local}

En el caso de La Matanza la adhesión a la nueva ley se realizó en mayo de 2007 (ratificado por la ordenanza municipal 15656) y se creó el Servicio Local de Promoción y Protección de Derechos. La adhesión a la ley 13298 y la consecuente creación del Servicio Local se produjo en el marco de diversas acciones en materia de política de niñez acordes al nuevo "enfoque de derechos" que se venía desarrollando en el municipio. De este modo, se resalta que durante la década de 2000 se crearon diversos dispositivos: el Consejo Municipal de Chicos y Jóvenes (año 2002), la Dirección de Juventud (año 2003), el programa ANDAR y equipos de fortalecimiento familiar en 2004, y el programa de acogimiento familiar en 2005 (que fue el primer programa alternativo a la institucionalización). Estos programas dan cuenta de que las políticas de niñez tenían un lugar destacado en la agenda local y que la implementación de la ley 13298 en el municipio fue entendida en el marco (o en el intento) de construir un sistema local de promoción y protección de derechos.

Luego de la creación del Servicio Local, el municipio creó también la Dirección de Coordinación del Sistema de Promoción de los Derechos de los Niños (Dec1979/08), dentro de la cualpasan a inscribirse los dispositivos existentes(algunos reconvertidos) y se amplió la oferta programática: programa por chicos con menos calle en 2008, programas Podes y Propiciar en 2009, Programa de responsabilidad compartida ENVION en 2012, programa para la prevención y atención inmediata del abuso sexual infantil en 2013 y programa familias afectivas de sostén y programa Ahijar en 2014

En este marco de una propuesta de política local integral con lógica de sistema para abordar problemáticas de la niñez, el Programa Propiciar se puso en marcha en abril de 2009 y desde entonces ha recibido en promedio 300 solicitudes de intervención por año provenientes principalmente de los juzgados de garantías del joven, aun cuando 
también atiende demandas del sistema educativo y algunas situaciones directamente detectadas por el Servicio Local de Promoción y Protección de Derechos del municipio. ${ }^{14}$

El Propiciar plantea como eje de la intervención el trabajo de operadores sociocomunitarios en territorio, quienes realizan una tarea de vinculación y seguimiento de los jóvenes, donde también toman contacto con el grupo familiar y realizan acciones de fortalecimiento(si la situación lo permite). Cada estrategia de intervención se sustenta en la construcción de un vínculo -entre el operador y el adolescente- y requiere de la articulación con otros organismos estatales y/o con organizaciones de la sociedad civil.

Desde su mismo diseño y luego en su implementación, el Programa se enfrenta a definiciones y desafios que ponen en tensión la coherencia de sostener el enfoque de derechos ante la urgencia de intervenir en situaciones de exclusión dura donde se presume que un adolescente ha trasgredido la ley (decimos se presume porque la declaración de no punibilidad implica que, salvo excepciones, la investigación no continúa).

\section{La (re)definición del problema y el encuadre que propone}

\section{el Programa Propicia}

A fines del año 2008, es decir a poco más de un año de vigencia de la nueva ley, el Servicio Local de Promoción y Protección de Derechos de La Matanza comenzó a recibir solicitudes de intervención provenientes de los Juzgados de Garantías del Joven de La Matanza y de las Fiscalías del Fuero de la Responsabilidad Penal Juvenil (como se mencionó creados por la Ley 13.634).En éstas se pedía vía oficio judicial que se indague e intervenga en posibles situaciones de vulneración de derechos de jóvenes en conflicto con la ley penal que fueron declarados inimputables por edad. ${ }^{15}$

En un principio dichas situaciones fueron abordadas por los equipos técnicos de las tres sedes del SLPPD pero pronto la coordinación del Servicio advirtió que las problemáticas a las que debían hacer frente rebasaban el alcance del dispositivo previsto. De allí que desde la Coordinación del Sistema de Promoción de los Derechos de los Niños se planteó la necesidad de diseñar otro dispositivo (específico) en función de las situaciones en que se encontraban dichos jóvenes.

En este punto vale una primera reflexión en torno a la construcción de la agenda local respecto al problema y la consecuente decisión política al respecto. Recordemos que los jóvenes entran por un presunto delito pero al ser no punibles la investigación (o proceso) penal cesa. Por tanto es cuestionable tomar como dada la definición de adolescentes en conflicto con la ley penal. Muy rara vez se continúa la investigación penal para determinar la situación del adolescente implicado en el hecho.
Aquí emerge una cuestión que ya era crítica (y blanco de críticas) en el sistema tutelar donde bajo un discurso de protección se 'dejaba a un lado' la cuestión penal,pero en el momento de adoptar medidas nunca dejaba de considerarse esa situación que dio origen a la intervención; de tal modo que ese supuesto delito se hacía presente cuando se lo consideraba como síntoma para elaborar el diagnóstico de la situación socio-familiar o para atribuir alguna característica personal de peligrosidad en base al hecho (Villalta 2004).

Ahora bien, entonces ¿qué debe hacer el Estado? Una opción sería no hacer nada. Podríamos entenderlo como un garantismo pasivo, donde se actúa de acuerdo a la ley (penal) en cuanto a la inimputabilidad y no se activan otro tipo de intervenciones. En cierta medida se saldaría la mencionada crítica a los art. 63 y 64 de la ley y no se abre la sospecha de intervenciones solapadamente tutelares. Pero claro que esto no modificaría la situación de vulneración de derechos en que se encuentran los adolescentes ni tampoco la demanda planteada desde el poder judicial.

Justamente, desde el poder judicial, en lo que podríamos entender como otra forma de posicionarse respecto al problema (ya no en términos penales), la cuestión es replanteada (acorde a lo que establece la ley) en términos de derechos vulnerados que requieren una intervención social pero no dictamina la medida de protección. Nuevamente, esto también podría entenderse como una opción para encubrir bajo un halo de protección (ante derechos vulnerados) una intervención que promueva la institucionalización y el encierro (privación de libertad), lo que podría traducirse como una continuidad de las viejas políticas del patronato. Esto, como fue señalado es una de las principales objeciones que se plantean a la ley 13634 .

En el caso de La Matanza, los oficios solicitaban la intervención del SLPPD pero no disponían el tipo de medida. La posición asumida por el Municipio consistió en no desentenderse pero tampoco caer en una continuidad de la intervención punitiva a través de medios administrativos y extrajudiciales. Para ello los actores locales se valieron de marco (conceptual, normativo e institucional) planteado por la ley y de la propia experiencia. Desde el SLPPD ya se habían atendido situaciones con problemas similares pero no adquirían una magnitud tal que le otorgase envergadura para incorporarlo como asunto en la agenda del área. Estas intervenciones previas fueron importantes para tener un conocimiento de la complejidad del problema a abordar y de los límites propios de las intervenciones planteadas desde el Servicio Local.

Al respecto, los responsables del Sistema de Promoción de Derechos realizaron un análisis de los 168 oficios recibidos hasta ese momento (abril del 2009) en los que aparecían niños y/o adolescentes menores de 18 años sospechados de un delito penal. En ellos casi la totalidad se refería a varones, la amplia mayoría entre 12 y 17 años, más de la mitad de los expedientes planteaba situaciones de robo y hurto (56\%) y sólo había un caso 
de homicidio. En todos los casos provenían de familias de bajos recursos y en muchos se mencionan condiciones de hacinamiento. Casi no hay vínculo con el trabajo (sólo 8 manifestaron trabajar o haber trabajado), y en los casos que se registraba el dato el 96\% no concurría a la escuela. Este análisis resaltaba el vínculo con las drogas o los problemas de adicción como una constante. También hacía mención a biografias signadas por la violencia desde edades tempranas y, finalmente, observaba una tendencia en cuanto a que se incrementan los niveles de violencia en el tipo de delito que se le imputa cuando se trata de situaciones asumidas grupalmente.

Esta caracterización preliminar fue incorporada por los responsables locales en el marco del posicionamiento político-conceptual encuadrado en el enfoque de derechos y en la ley 13298. Cabe destacar que en ningún momento la instancia local interpretó o buscó señalar alguna contradicción en cuanto a la ya comentada potestad otorgada por los art. 63 y 64 de la ley 13634 al juez de garantías pero sí entabló un vínculo directo con el departamento judicial, principalmente a través del ministerio público. En este punto vale resaltar la autonomía que, más allá de la particularidad de esta ley, asume un municipio como La Matanza cuya capacidad de posicionarse respecto a la autoridad provincial y al poder judicial vienen dadas también por su peso político (poblacional, electoral y presupuestario)

Pero además de esta característica del municipio, vale recordar que el Servicio Local fue creado en la órbita de la jefatura de gabinete, lo que le posibilitó también una relación directa con una instancia clave en la toma de decisiones, así como también el acceso a recursos y, en consecuencia, la incidencia en la agenda. Esta inscripción institucional permitió mantener al Servicio Local dentro de un "paraguas de protección" frente a los atravesamientos político-partidarios y/o territoriales, e incluso ante la posibilidad de un posible desborde por un aumento de demanda por parte de distintas áreas del propio municipio. Estas fueron las condiciones institucionales que posibilitaron que la Coordinación del Sistema de Promoción de los Derechos de los Niñospudiese planificar una nueva modalidad de intervención. En febrero de 2009 comenzó a diseñarse el programa y en abril del mismo año se inició su implementación. A partir de las características de la problemática y de los jóvenes se decidió que el mejor modo de abordar el tema sería mediante la intervención de operadores sociocomunitarios que trabajarían con los jóvenes en el territorio, reforzando a los grupos familiares (cuando las condiciones lo permitiesen) y articulando con otros organismos estatales o de la sociedad civil en función de las situaciones diagnosticadas.

De este modo, surge el Programa Propiciar que definió el problema en términos de vulneración de derechos -algo que resulta afín a cualquier intervención del SLPPD- pero a la vez 'recogió el guante' de la situación de un (potencial) conflicto con la ley penal y define esta situación en términos de 'riesgo penal': "La situación de riesgo, estará dada por aquellas situaciones en que los niños/jóvenes se encuentran insertos en espacios con sistemas de reglas y lógicas que legitiman y/o favorecen el desarrollo de prácticas delictivas y donde los espacios de reproducción de los valores y normas socialmente aceptadas son débiles o inexistentes. Estas situaciones no necesariamente implican la existencia de un delito penal imputado, se trata de llegar -y de captar-, a niños y jóvenes que pueden estar cometiendo delitos (y no fueron detenidos) o que se encuentran en procesos de internalización de normas y valores negativos para la vida en sociedad" (Programa Propiciar).

Acá vale una segunda reflexión: ¿qué tan coherente es esta categoría con la ley y el enfoque de derechos? La respuesta requiere sopesar su análisis en el contexto de su enunciación y de su aplicación. A priori, la definición en términos de riesgo generalmente utilizada como forma de adjetivar la condición misma del niño/a o adolescente ha recibido varias críticas y puede encajar en el paradigma de la situación irregular. ${ }^{16}$ Sin embargo, el Programa no se propone como una continuidad del problema planteado desde la instancia judicial (la supuesta infracción de la ley), lo que hubiese llevado a construir un sustituto (o una continuidad) de medidas de libertad vigilada o de reparación del daño. ${ }^{17}$ Por el contrario, el Programa toma en consideración el contexto de los adolescentes y las múltiples situaciones de vulneración de derechos que, en todo caso, llevaron a la emergencia de un hecho delictivo.

El Programa considera la situación de los jóvenes como un encadenamiento de vulneraciones (de derechos) previas: marcados por privaciones en sus necesidades básicas, insertos en escenarios de violencia (como un código de intercambio cuasi naturalizado), trayectorias signadas por la exclusión educativa y un notorio déficit en la inserción laboral de los adultos de las familias. Se entiende que ese contexto condiciona y promueve (aunque desde ya que no determina) la infracción a la ley, o dicho de otro modo, la inserción en redes delictivas (de las que en ocasiones forma parte la familia o el grupo de pares del que participa el adolescente en cuestión). Tal como se expresa en el documento base del Programa:"...la problemática central no tiene que ver con el acto delictivo, sino con una serie de privaciones de derechos que concluyen en la ruptura de la norma... entendiendo al delito como la manifestación de una serie de privaciones y vulneración de derechos que concluyen con la trasgresión de la norma". En tal sentido, las intervenciones del Programa están focalizadas en jóvenes en situación de 'riesgo delictivo' y se considera la especificidad de cada situación para definir estrategias de acompañamiento (que apuntan a la integralidad y se fundan en la construcción de un vínculo personalizado) en articulación con organizaciones y referentes territoriales.

Si bien este primer posicionamiento redefine el sentido punitivo más explícito y directo de la intervención, bien podría constituirse como una medida de índole tutelarista, propia del régimen de minoridad, donde bajo la apelación a la protección se instituye 
una forma de control que termina siendo además discrecional y sin derecho a defensa. Este señalamiento consideramos que deviene en una advertencia latente a lo largo de la implementación del Programa y obliga a una definición clara de objetivos, de la modalidad de abordaje y también de los límites mismos a la intervención. ${ }^{18}$

Un tercer señalamiento, que también planteamos como una precaución continua en la intervención refiere a la definición y el alcance de la categoría 'riesgo delictivo'. Al respecto, una cuestión clave es sostener esa definición en torno a la vulneración de derechos, lo que impide referirse exclusivamente a las características personales de cada adolescente (lo que generaría efectos estigmatizantes) pero sí se toma en cuenta el contexto de vínculos interpersonales y la existencia o no con redes y/o actividades delictivas. En tal sentido, cuando se plantean líneas de acción, se debiese ponderar la cuestión de los vínculos interpersonales para la consolidación de referentes y ámbitos de sociabilidad no involucrados en acciones delictivas y asimismo, cuando se plantean acciones de prevención, éstas debiesen realizarse para efectivizar derechos y no tanto con la mirada puesta en evitar el delito (cargando en los adolescentes un destino inexorable).

Un cuarto señalamiento refiere a la capacidad del programa de definir estrategias singulares de intervención bajo un horizonte de universalidad y construcción de ciudadanía. Esto refiere a la necesidad de llevar a cabo estrategias de acompañamiento personalizadas (no son todos los adolescentes que viven en condiciones de privación los que se involucran en acciones delictivas) pero, a la vez, hacerlo con objetivos de mediano y largo plazo que permitan a los jóvenes el acceso a derechos y a ámbitos públicos propios de la edad (escuela, clubes, talleres, etc., donde se vinculen con otros pares y, en lo posible, conformen ámbitos heterogéneos en cuanto a la procedencia social) que los posicione como sujetos con autonomía y capacidad para tomar decisiones responsablemente.

Además de estos señalamientos que aluden a la conceptualización y definición del problema y al diseño y abordaje del Programa, también se presentan otras tensiones más relacionadas con la puesta en marcha del Programa.

\section{Las tensiones en la implementación y el desafio de la corresponsabilidad}

El paradigma de la Protección Integral supone un nuevo modo de pensar los problemas de manera integral, reconociendo su multidimensionalidad y que requiere intervenciones de una multiplicidad de actores que deben involucrarse para garantizar el cumplimiento de los derechos de los niños. Esto implica romper con la lógica sectorialista y plantear las intervenciones dentro de una lógica de corresponsabilidad, que supone compartir obligaciones y compromisos en un marco de trabajo relativamente común.
Las intervenciones dentro de la lógica de la corresponsabilidad remiten en primer lugar a entender a los derechos indivisibles de los sujetos en la implementación de una política. En este caso, son los actores encargados de llevar a cabo una política los que deben articular la intervención. Las problemáticas que aquejan a los jóvenes no son instancias inconexas que pueden ser resueltas en espacios diferentes y sin vinculación entre sí. El abordaje dentro de la lógica de la corresponsabilidad debe estar atravesado por la integralidad en esquemas de responsabilidad compartida.

En este punto vale una reflexión. El postulado de integralidad guarda correspondencia directa con el principio de indivisibilidad de los derechos (propio del enfoque de derechos). Ahora bien, en el caso del sistema de protección y promoción de derechos de la niñez y adolescencia, hay tres cuestiones interrelacionadas que se ponen en juego: uno se vincula a la necesidad de contrarrestar la lógica de las intervenciones de la minoridad donde aquello que no encaja en lo que se considera normal es expulsado a dispositivos de encierro y corrección. Además, esta construcción de sentido se asentaba en un esquema de decisión vertical anclado en la figura del juez donde no se consideraba la voz del niño; en tal sentido, el derecho a ser escuchado es un pilar de en la construcción de las nuevas estrategias. Asimismo, la nueva orientación política no apunta sólo a reemplazar el circuito judicial por uno de índole administrativa, sino a instrumentar estrategia intersectoriales y participativas que actúen como redes de sostén ante situaciones de vulneración de derechos. Lo dicho implica plantear estrategias de intervención ancladas en la articulación de diferentes organismos, la participación de los distintos actores y con los adolescentes en un lugar activo.

Propiciar se puso en marcha en abril de 2009 y desde entonces ha recibido alrededor de 2300 solicitudes de intervención provenientes principalmente del sistema judicial, pero también del sistema educativo, de otros organismos del ejecutivo o vía "demanda espontánea" del sistema de promoción de derechos local.

La lógica territorial de intervención del programa ${ }^{19}$ fue pensada a partir de la experiencia de un programa existente en el propio Servicio Local, el "Proyecto Local Por Chicos con Menos Calle" donde se trabaja con los niños en situación de calle desde las "ranchadas" con operadores socio-comunitarios. Siguiendo esta línea de intervención, la estrategia de abordaje del programa se pensó a partir de la intervención de operadores que trabajan con los jóvenes desde el territorio. De este modo, el trabajo en el territorio se organizó a partir del armado de equipos de operadores que cubren los tres cordones en los que ha sido dividido el territorio. ${ }^{20}$ Como resultado de la participación en una red barrial, el programa tiene un dispositivo específico -construido en ese espacio- que trabaja en tres barrios lindantes del municipio: puerta de Hierro, San Petersburgo y ${ }^{17}$ de marzo. Dichos barrios, se destacan por registrar múltiples privaciones y altos niveles de violencia social y actividades delictivas. 
El modo de abordar las problemáticas de los jóvenes supone la puesta en marcha de un proceso complejo. Luego de mantener una entrevista inicial con los jóvenes y sus referentes familiares en la sede del programa y realizar una primera definición del problema, se determina la pertinencia de continuar la intervención y se asigna la situación a los operadores. Estos comienzan la intervención a partir de encuentros con los jóvenes que buscan la construcción de un vínculo de confianza, una vez que esto se logra, en conjunto con el adolescente y -en los casos en que es posible- también con sus referentes familiares se diseñan e implementan las estrategias para la restitución de derechos. Los resultados de este proceso dependen de diversas variables que entran en juego en cada situación.

En la implementación de esas intervenciones la articulación con las instancias que (según la ley) forman parte del sistema -caracterización recuperada en las conclusiones- ha estado teñida por tensiones que la obstaculizaron. Los obstáculos a la corresponsabilidad aparecen en los distintos sistemas que deben participar de los procesos de intervención, tales como el sistema judicial, el sistema educativo, de salud, etc. y pueden resumirse en: resistencia al nuevo paradigma por parte de actores clave en las instituciones involucradas; desconocimiento de cómo actuar en este nuevo marco institucional, y falta de recursos en casi todos los organismos encargados de participar en las intervenciones.

Las voces más notorias que se han pronunciado en contra de esta nueva institucionalidad se inscriben en el sistema judicial y más precisamente en lo que anteriormente constituyera el fuero de menores. Estos sectores entendieron a la implementación del paradigma de la Protección Integral como una pérdida de poder frente al ejecutivo. Aunque la transformación del sistema judicial, si bien supuso la desaparición de las figuras y competencias de la doctrina anterior, mantuvo a muchos de esos actores en lugares relevantes (cuestión que se hace muy visible en el caso de La Matanza). De este modo, los anteriores Jueces de Menores pasaron a ser Jueces de Garantías del Joven y lo mismo sucedió con los Fiscales, con lo queesosactores no solo vieron reducidas sus competencias sino que además se vieron obligados a tener que articular con nuevos actores en un marco legal respecto del cual, en muchos casos,se habían pronunciado en contra.

A esto se le suma que al nuevo fuero se han incorporado sujetos con posicionamientos y lógicas que apoyan el Paradigma de la Protección Integral haciendo más heterogéneo el posicionamiento del sistema judicial y aumentando también la conflictividad en torno de los procesos judiciales.

En este marco de diversidad de posiciones del sistema judicial, la implementación de un programa como el Propiciar, que se crea y se enmarca en el nuevo paradigma, ha tenido que adaptar una estrategia de articulación en función de esa heterogeneidad de los actores judiciales. A modo de ejemplo, el fuero penal Juvenil contaba con dos fiscales, uno afin al nuevo paradigma (o al menos dispuesto a discutir acciones en conjunto) y otro en franca oposición. El Propiciar diseñó y propuso un protocolo para articular con éstos pero sólo pudo implementarlo con el primero dado que el segundo no aceptó siquiera reunirse para discutirlo.

Si bien los titulares de cargos judiciales no afines al nuevo paradigma se han negado a participar de espacios compartidos con el Programa Propiciar o el Servicio Local para acordar criterios de intervención y acciones en conjunto, esto no ha implicado que no haya relación alguna. En lo que en principio podría parecer paradójico, son estos actores los que más solicitan la intervención del programa. Lo cierto aquí es que lo hacen bajo la lógica de la "derivación" (mas asimilable a régimen tutelar), a través de la cua "exigen" la intervención del Propiciar para todo niño inimputable que haya cometido un delito, más allá de que se haya o no constatado la existencia de derechos vulnerados como marca la legislación..$^{21}$ De este modo, este tipo de acciones que se dan en el marco de esa ambigüedad ya señalada de la nueva ley, da margen para que distintos actores judiciales traten de imponer criterios punitivos para las intervenciones del Programa, o bien, provocar una magnitud de solicitudes que tiendan a su colapso.

Ahora bien, aunque las posiciones opositoras del sistema judicial han sido las más visibles, las resistencias al nuevo paradigma y, por ende, los obstáculos a la corresponsabilidad se encuentran también en otros ámbitos como educación, salud y en organismos dependientes del propio municipio. En el caso del sistema educativo, el principal obstáculo tiene que ver con la trasformación de la lógica de intervención y la falta de pautas claras de acción hacia adentro del propio sistema. Durante la doctrina del patronato, las escuelas y más precisamente los equipos de orientación escolar, identificaban determinadas problemáticas que afectaban a los niños (abusos, adicciones, pobreza, etc.) y sin perjuicio de continuar la intervención, dejaban la resolución del problema en manos del Juez de Menores, quedando la responsabilidad en este último. Cabe aclarar aquí que no intentamos hacer generalizaciones respecto al accionar de los docentes y al compromiso de los trabajadores sociales y psicólogos de los equipos de orientación escolar (que por cierto era muy heterogéneo).

Desde la experiencia del Propiciar, una de las principales dificultades tiene que ver con que el resto de los actores no saben qué esperar del Programa, principalmente porque no se tienen en cuenta las limitaciones y competencias del mismo. En la medida que el Propiciar es parte del Servicio Local, asume una lógica de intervención muy similar y, de hecho, utiliza el mismo protocolo que el servicio local acordó con la instancia de inspección de los equipos de orientación escolar. Sin embargo, en la práctica, gran parte de esos equipos sostienen desconocer ese protocolo y reclaman que se tome el "caso" que se está "derivando", desconociéndose y obstruyendo de este modo la puesta en práctica de una lógica de la corresponsabilidad..$^{22}$ Se advierte en muchos casos que existe una reticencia a tener responsabilidad en el diseño e implementación de las estrategias en- 
tendiéndose la no derivación como sinónimo de no accionar. Dicho de otro modo, muchos sectores del sistema educativo consideran que su accionar se limita a la derivación de las situaciones para que sean resueltas por otros y desligarse de la responsabilidad.

En cuanto a la articulación con el sistema de salud -y resaltando en este apartado los obstáculos a la corresponsabilidad- pueden verse dos lógicas totalmente diferentes. Por un lado, el personal médico presenta un alto grado de desconocimiento -e indiferenciarespecto a la existencia de la nueva legislación al punto que llegan a darse situaciones en las que se niegan a atender a niños sin órdenes judiciales o sin la presencia policial En contraste, los equipos de trabajadores sociales además de tener conocimiento, participan de espacios de diálogo conjunto. Pese a esta disposición, el principal problema que plantean es la falta de recursos. Con frecuencia se presentan situaciones donde se pone en evidencia la dificultad para acceder a tratamientos ambulatorios, acompañantes terapéuticos o internaciones psiquiátricas, entre otras.

En este punto, el principal problema que se presenta para el Propiciar resulta de que dado que es una instancia de articulación para la restitución de derechos y al no encontrar un organismo que realice los tratamientos en relación a los problemas de salud (derecho a la salud), las situaciones que aborda no encuentran resolución en ese plano, quedando estancadas la intervenciones y convirtiéndose en un cuello de botella. En cuanto a salud mental, esto no ha podido ser resuelto por la implementación de la nueva ley (26657). Si bien esta nueva legislación propone ordenar circuitos institucionales, procedimientos y competencias de un modo acorde al enfoque de derechos, la no adecuación de los dispositivos de salud y la falta de asignación de recursos hace que su implementación sea deficiente. Paradójicamente, incluso, ha empeorado la posibilidad de articulación con el área de salud mental dado que los nuevos procedimientos, competencias y funciones legales (que no se cumplen) han reemplazado los acuerdos y protocolos anteriores, con los que se trabajaba. Se resalta aquí que si bien la nueva ley de salud mental constituye un marco superador a partir del cual abordar cuestiones de adicciones y demás problemas de salud mental, sin embargo, las dificultades para su implementación generan un vacío al momento de proponer estrategias de restitución de derechos.

Dado que el Propiciar opera básicamente como una instancia de articulación, la escasez o inexistencia de dispositivos específicos para la atención o la falta de recursos determinados, colocan al Programa en un lugar de reclamos, y frecuentemente se convierte en la cara visible de la carencia de recursos tanto municipales como provinciales o nacionales.

A su vez, un obstáculo que no puede pasarse por alto tiene que ver con el propio Programa como parte del Servicio Local. Aquí también existen resistencias y carencia de recursos. Las resistencias aparecen cuando los propios equipos dejan de actuar desde la lógica de la corresponsabilidad y de modo análogo a lo que eran las intervenciones del "Juez de Menores" intentan dar respuestas encapsuladas y totalizantes a problemáticas complejas que requieren múltiples intervenciones (además lo hacen con mucho menos recursos); o bien, en contrapunto, pueden también volcarse a la derivación rápida a otros organismos - $\mathrm{O}$ a diferentes dispositivos del mismo organismo- para que resuelvan y desentenderse de la situación. Si bien estas situaciones no definen el accionar del conjunto del organismo ni del Programa, se resalta que en ocasiones aún perduran prácticas (lógicas institucionales y disciplinarias) del modelo anterior.

La cuestión de los recursos resulta un tema clave y deficitario en la implementación de casi todos los programas y dispositivos enmarcados en la nueva normativa de niñez y adolescencia. En este caso, la escasez de recursos se pone de manifiesto en el déficit de personal técnico y profesional para atender a la demanda existente (que se agrava cuando no puede construirse un marco de intervenciones corresponsables para abordar la situaciones que se presentan) y para la propia participación en espacios de articulación a nivel territorial, como por ejemplo redes barriales. Los recursos que se asignan a los SLPPD dependen del ejecutivo municipal (Fondo de Fortalecimiento de Programas Sociales Ley 13.163) y desde su creación constituyeron una suerte de negociación con la Provincia de Buenos Aires para adherir mediante convenio o no a la nueva ley. Cabe aclarar que los fondos no son específicos para la implementación de dichos Servicios Locales. El programa Propiciar se financia con recursos del municipio de La Matanza y recursos del Ministerio de Desarrollo Social de la Provincia de Buenos Aires siendo estos los que pueden decidir la ampliación del presupuesto. ${ }^{23}$

Estas dificultades operan como restricciones para una intervención corresponsable con perspectiva integral y, en cierto sentido, redefinen los límites y el alcance del programa. En contrapunto, también queremos destacar tres instancias de articulación que resultaron positivas: con el Consejo Local, con el Centro de Referencia y con el Centro Provincial de Atención de adicciones(CPA).

En mayo 2009 se presentó el Propiciar en el espacio de articulación intersectorial del Consejo Local, ${ }^{24}$ sumándose la coordinación del programa a la participación en la Comisión Penal de ese espacio. Desde dicha comisión, el Propiciar pudo avanzar en la creación de protocolos de articulación principalmente con: las Defensorías del Joven, el Centro de Referencia, con una de las Fiscalías de Responsabilidad Penal Juvenil y con el Centro Provincial de Atención de adicciones. Asimismo, los protocolos de articulación del Servicio Local con organismos como la Asesoría de Menores o el sistema educativo se extendieron al programa.

En el caso del Centro de Referencia, organismo creado para el cumplimiento de medidas alternativas a la privación de la libertad ambulatoria para jóvenes imputables (entre 16 y 18 años de edad) en el inicio del Propiciar se acordó que si el juez aplicaba una 
medida de seguridad sobre un niño inimputable, sería ese organismo el que tomara intervención. Esto en su momento fue importante porque sobre una cierta ambigüedad -ya mencionada- de la ley se explicitó un límite respecto a los alcances del Programa que se sustenta en intervenciones de carácter voluntario por parte de los jóvenes, lo que posibilita otra forma de construir el vínculo, acompañarlos y pactar con ellos. Si bien en ese período inicial (y fundacional) del Programa esto sirvió para poner un límite a una intervención de carácter punitivo que el sistema judicial aplica sobre adolescentes inimputables, dada el escaso o nulo trabajo territorial del Centro de Referencia, en el año 2016 se acordó -tal como lo indica la ley- que el equipo local interviene a los fines de establecer una estrategia de intervención para la externación del niño/adolescente en cuestión. En este punto vale un señalamiento a modo de advertencia con respecto al abordaje, aun cuando la intervención se piense a partir de la vulneración de derechos y la concepción del eslabonamiento previo al hecho supuestamente delictivo (insistimos en que el proceso penal no continúa y no se prueba el delito) tal como se plantea en el posicionamiento conceptual del Programa, se corre el riesgo de no sostener la estrategia sobre un acuerdo voluntario, lo que podría implicar un giro no menor en la forma de establecer el vínculo y en el posicionamiento del propio adolescente en cuestión. Dado que estas intervenciones son muy recientes, queda abierta la interrogante para verificar si el accionar del Programa en estas situaciones logra diferenciarse del esquema punitivo -o por el contrario si se constituye en un continuo del sistema penal juvenil-.

En cuanto a defensorías del joven y fiscalía de responsabilidad penal juvenil, el protocolo de articulación apuntó a acordar qué situaciones serían presentadas en el programa Propiciar (individualizándose previamente la existencia de situaciones de vulneración de derechos), como así también a simplificar y agilizar los circuitos de acceso al mismo.

Por último, con respecto al CPA, se diseñó un dispositivo de articulación e intervención en conjunto para los jóvenes que participan del programa y presentan problemas de consumo de sustancias psicoactivas. Dicho dispositivo se creó a raíz del diagnóstico previo a la creación del programa en el que se alertaba de que esta problemática estaría presente en un gran número de jóvenes. Es por ello que en conjunto con el CPA se organizó el armado de una instancia para el tratamiento grupal y otra individual que funcionan en la sede del programa.Aun así, en materias de adicciones urge establecer modalidades de intervención activas por parte de los actores de salud, con agentes u operadores que trabajen en el territorio y que realicen acciones de seguimiento y acompañamiento de los adolescentes con problemas de consumo. También se necesitan dispositivos de intervención efectivos ante situaciones de crisis que, en ocasiones, pueden incluso requerir la internación (para ello hacen falta actores estatales que actúen responsablemente en el marco de la ley).

\section{Algunas conclusiones: mirando el Propiciar y a propósito del debate en torno a la edad de punibilidad}

El Propiciar muestra la complejidad del actual escenario para implementar un programa acorde al enfoque de derechos. Esta complejidad viene dada, desde ya, por la propia naturaleza del problema sobre el que se interviene pero también por los déficits y vacíos en materia de institucionalidad estatal en materia de infraestructura urbana básica y políticas sociales en general y, en particular, en la construcción de la nueva institucionalidad del sistema de protección y promoción de derechos. A su vez, en los barrios de incidencia del Programa se ponen de manifiesto las acciones estatales de control punitivo sobre los adolescentes como prácticas cotidianas -lo que desde ya plantea una presencia estatal contradictoria al postulado enfoque de derechos-.

Como pudo apreciarse en el relato resulta llamativo el escaso protagonismo del ministerio provincial a cargo de la puesta en marcha del nuevo "Sistema" de Promoción y Protección de Derechos. Las comillas refieren a que la denominación sistema se parece mucho más a un anhelo (en el mejor de los casos) que a las características de las acciones e intervenciones que se desarrollan. Si bien es poco el tiempo transcurrido desde la nueva ley, el grado de fragmentación de las acciones es notorio y resulta muy dificil la pretensión de construir un sistema integral sin los recursos necesarios y el ejercicio de una función de coordinación desde el nivel central. De hecho el Programa analizado pone en evidencia un área de vacancia en las políticas provinciales (algo que si bien no formó parte de este análisis, también puede replicarse en cuanto al déficit de coordinación de la Nación con respecto a las provincias en estas áreas).

Sin embargo, la experiencia del Propiciar muestra que desde el nivel local es posible implementar políticas que promuevan una perspectiva integral y territorial, aun cuando se trata de uno de los problemas más arduos y complejos para sostener de manera coherente y desde una política activael enfoque de derechos. Algunos aspectos claves que fueron mencionados en el relato refieren a: la capacidad de los actores locales para redefinir el problema en clave de derechos, la construcción del Propiciar desde una instancia con autoridad (la Jefatura de Gabinete del Municipio), la capacidad de negociar y articular con otros actores, explicitar los límites de la intervención, recuperar experiencias anteriores y apostar al trabajo territorial. En el relato también aparecieron desafíos, tensiones y límites del Programa, tanto en lo que hace a su carácter articulador (por tanto dependiente de la permeabilidad de los otros actores para avanzar en el esquema de corresponsabilidad), asî como a cuestiones de coherencia conceptual respecto a las intervenciones para no caer en abordajes de índole tutelaristas. La dificultad de articular no resulta llamativa respecto de algunos actores del poder judicial pero sí con dos sectores claves de la política social como son educación y salud; nuevamente en este punto resaltamos la necesidad de potenciar una instancia de autoridad política que ejerza la función de coordinación. 
Cabe destacar las limitaciones del Programa en cuanto a su implementación en contextos comunitarios donde los niveles de exclusión social -material y simbólica- y el abandono institucional han posibilitado procesos de segregación espacial, devenidas en una suerte de guetos urbanos sin condiciones básicas de habitabilidad. La estigmatización que sufren estas comunidades construye un 'otro' considerado peligroso, crean y refuerzan fronteras socioculturales que, sumado a la desigualdades económicas y las intervenciones punitivas, generan un proceso de guetización y de aislamiento de esos barrios. Estos procesos de segmentación y segregación reducen las oportunidades de sociabilidad informal entre las clases sociales e inciden, en particular, en las condiciones objetivas y subjetivas de aislamiento de los más vulnerables (Carman y Segura 2013). Estos contextos de exclusión, de estigmatización y de persecución policial sobre los jóvenes constituyen un condicionante que dificulta la consecución de los objetivos propuestos por el Programa; incluso, aun cuando el programa logre intervenciones exitosas, éstas no dejan de ser situaciones particulares que no cambian la dinámica socioterritorial. Esto último implica, en un nivel más general, la articulación con un proyecto de desarrollo económico que genere puestos de trabajo decentes, y en el plano local, la construcción de una infraestructura urbana básica en estos barrios, un servicio de transporte público que garantice la movilidad espacial, la construcción de espacios públicos de esparcimiento, una oferta de servicios sociales de educación y salud de calidad, más una oferta pertinente de programas socioeducativos y de promoción de derechos para la niñez y la adolescencia.

Finalmente, en un contexto político donde se impulsa con claras intenciones de demagogia punitiva (Zaffaroni 2011) un debate en torno a la baja de la edad de inimputabilidad, entendemos que la respuesta estatal a una problemática resultante de vulneraciones de derechos producto del déficit y/o ausencia de políticas públicas, no se resuelve poniendo el foco en los jóvenes en conflicto con la ley penal. Situar allí la cuestión sólo colabora para fortalecer la construcción una imagen de los adolescentes y jóvenes de los sectores populares como peligrosos. Aun reconociendo que a nivel nacional está pendiente la creación de un régimen de responsabilidad penal juvenil que les dé un tratamiento acorde al debido proceso a los adolescentes y que priorice medidas de reparación y/o alternativas a la privación de libertad. El debate en torno a la edad de punibilidad no puede ser el foco de esta reforma y mucho menos plantearse como la resolución delas situaciones de adolescentes inimputables con episodios de conflicto con a ley penal. La respuesta desde el Estado debe ser la de garantizar y efectivizar derechos a la par de abordar la responsabilización de los jóvenes ante las situaciones que implican un atropello real o potencial a derechos de terceros y/o de la comunidad. En tal sentido, el Programa Propiciar constituye una referencia al respecto (como así también el trabajo que despliegan diversas organizaciones territoriales en el conurbano). No se trata de definir edades de punibilidad. ni de considerar a los adolescentes únicamente como sujetos de derecho porque acceden a un debido proceso. Se trata de entender que los adolescentes que llegan a la ruptura de ciertas normas legales, lo hacen como corolario de un proceso que los empuja a ese lugar: un sistema educativo que expulsa, un sistema de salud colapsado y sin recursos que no los reconoce como sujeto y al cual no pueden acceder, trayectorias familiares atravesadas por la pobreza, el desempleo y en muchos casos la violencia; y por sobre eso el peso de la estigmatización en una sociedad de consumo que los invita permanentemente a consumir pero lo priva constantemente de los medios legales para efectivizarlo (cfr Reguillo, cit.).

El abandono institucional y la falta de políticas integrales en los barrios facilitan la inserción aespacios de sociabilidad atravesados por el delito y el consumo de drogas. A esto se agrega un sistema de "justicia" que -la mayoría de las veces- sólo se presenta a través de acciones punitivas y de fuerzas de seguridad (y un sistema político) con prácticas corruptas que, de manera informal, regulan los circuitos de drogas y armas, y que en muchos casos demanda a los jóvenes para la comisión de delitos que, posteriormente, los vuelve víctimas de la violencia policial. Al respecto, una investigación sobre políticas de seguridad y políticas penales que incluye el área del conurbano bonaerense y la CABA resalta que: "los jóvenes identificaron a la policía bonaerense como la principal fuerza con despliegue territorial en los espacios marginales de la provincia, aunque también mencionaron a la Gendarmería Nacional como fuerza con alta presencia. Así, las tres categorías que emergieron analíticamente como identitarias de las prácticas policiales en el control del espacio urbano, esto es marcación, intimidación y complicidad delictiva/ extorsiva, son extrapolables a las otras fuerzas de seguridad" (Guemureman 2015:18; el resaltado nos pertenece). Más que apuntar a los más jóvenes en los barrios, se debe poner el foco en las redes delictivas y en el accionar de las propias fuerzas de seguridad.

La propuesta del Programa apunta a la construcción de un dispositivo de acompañamiento que colabore en un momento crítico a generar experiencias vitales que fortalezcan el lazo social, lo que en ocasiones implica generar -a través del trabajo en red con las organizaciones sociales que trabajan en los barrios- un punto de quiebre en sus biografias y les posibilite encontrar (otros) ámbitos de pertenencia (y por tanto de referencia), en el marco del cumplimiento y la efectivización de derechos. El trabajo con los jóvenes a partir de la construcción de un vínculo de confianza (Gómez da Costa 1995) con referentes territoriales con capacidad de ejercer un sostén socio-afectivo en situaciones críticas y de promover la inclusión en espacios y proyectos significativos que impliquen una expansión de derechos, ha mostrado resultados más efectivos que las acciones mediáticas-punitivas (o demagógicas punitivas) de mano dura. ${ }^{25} \mathrm{La}$ revinculación con el sistema educativo (compleja pero posible), el acceso a los sistemas de salud y justicia, ${ }^{26}$, el acceso a espacios recreativos, deportivos y/o culturales, la desnaturalización de la violencia familiar, etc., son estrategias que los vuelve "parte" de un todo social que funciona como marco para desarrollar la acción. 
Por el contrario, las respuestas estatales punitivas generan al menos tres efectos: en un plano más general marcan la orientación, ponen el foco y crean sentido, en este caso refuerzan el estereotipo de los varones adolescentes y jóvenes de los barrios postergado y de los suburbios como peligrosos. De este modo, consolidan y plantean un enfrentamiento con un otro cada vez más excluido y -por ende- cada vez más antagónico (esta es la escena que recurrentemente muestran y construyen los medios de comunicación). A su vez, esto impacta -como cadena de secuencia lógica- en el territorio y allí destacamos otros dos efectos. Por un lado, en las propias fuerzas de seguridad, que lejos de estar exentas de la imagen de "los jóvenes peligrosos", son partícipes activos en la construcción de ese estereotipo y, por tanto, esta orientación refuerza el lugar de esos adolescentes/jóvenes como un potencial enemigo en el territorio. Finalmente, un tercer efecto tiene que ver con los propios jóvenes que no son inocuos ni pasivos ante la construcción de estos estereotipos y del lugar del chivo expiatorio de los males sociales del sistema (capitalista).

Con respecto a la forma en que los adolescentes tramitan esta acción discriminatoria y persecutoria, Didier Fassin analiza el sentido que adquiere esta experiencia que "no es, por cierto, exclusivamente intelectual. Se inscribe en los cuerpos de los adolescentes de dos maneras distintas y complementarias. Por un lado, los jóvenes comprenden lo que encarnan ante los ojos de la sociedad ('miren lo que son' se les dice). Por otro, incorporan esa representación que se les da de ellos mismos ('¡conviértanse en lo que son!' les ordenan). Esta puesta en juego del cuerpo -encarnación e incorporación- escapa en parte a la conciencia. Se la siente más que se la analiza. Se traduce en las emociones... en ese miedo ante los policías..." (Fassin 2016:34). Ante esto, las formas de (re)posicionamiento de los propios adolescentes pueden ser múltiples y variadas, aquí simplemente mencionaremos que, por un lado, en un sentido positivo puede generar una reapropiación y re-significación del mote despectivo (la llamada cumbia villera vale como ejemplo) o la puesta en acto de proyectos colectivos con fuerte identidad villera (como la revista Garganta Poderosa). Pero también, y este es el punto sobre el que queremos llamar la atención, las políticas que se apoyan en esta imagen de la peligrosidad de los adolescentes potencian las condiciones para la construcción de identidades juveniles refractarias (Reguillo 2004), donde el camino de las intervenciones de mano dura (y gatillo fácil) en un escenario de repliegue de la acción social del Estado y de contracción del empleo, en territorios que ya se encuentran en condiciones de guetización, puede marcar un derrotero al recrudecimiento y emergencia de nuevas formas de violencia.

Finalmente, está claro que el Propiciar por sí sólo no alcanza a dar respuesta a las situaciones complejas de exclusión social, acá marcamos ese límite y la necesidad de que el Estado se haga presente a través de políticas públicas y de servicios sociales de calidad que promuevan la inclusión y la movilidad social. Construir y sostener un horizonte de oportunidades efectivas para los más jóvenes en los barrios más postergados es un desafio y un deber inalienable de todo Estado Democrático y la condición misma para su sustentabilidad, en tanto ésta no puede estar desligada de la idea de igualdad y de justicia para las nuevas generaciones. Al respecto, vale un comentario autorreferencial del ya citado antropólogo Fassin, a propósito de la detención y el maltrato policial con su hijo y otros dos adolescentes en las periferias de París: “Tener que enseñarles a nuestros hijos lo trivial de la discriminación y la docilidad ante la injusticia lleva a un cuestionamiento serio sobre lo que significa, en una democracia, tal concesión obligada al Estado de derecho" (op. cit. 37). 

1 Ley nacional 22.278 , art 1 No es punible el menor que no haya cumplido dieciséis años de edad. Tampoco
lo es el que no haya cumplido dieciocho años, respecto de delitos de acción privada o reprimidos con pena privativa de la libertad que no exceda de dos años, con multa o con inhabilitación.

Los postulados del enfoque de derechos remiten a una serie de declaraciones, convenciones y tratados de alcance internacional elaborados en el marco del Sistema de la Organización de las Naciones Unidas. De manera sintética podemos mencionar los principios rectores del enfoque: universalidad, igualdad y no discriminación; participación (en materia de niñez y adolescencia implica el derecho a ser escuchado), información (producción y acceso) y exigibilidad. A su vez, estos principios se definen de manera indivisible, lo que re-

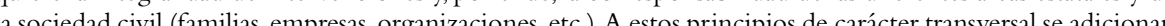
dos principios específicos tales como: progresividad y no regresividad, más la prioridad de los sectores má vulnerados y niveles mínimos de derechos. Los firmantes y garantes de estos postulados son los Estados nacionales e implica a cada una de sus áreas y niveles jurisdiccionales.Respecto a las implicancias institucionale del enfoque de derechos ver Abramovich y Pautassi (2009), para sus consecuencias en los procesos de políticas públicas ver Rossiy Moro (2014). Para revisar el proceso específico de la Convención Internacional sobre Derechos del Niño ver Pilotti (2001)

Sobre el giro conceptual ver Bellof(1999). Para una lectura crítica de las prácticas de gestión estatal bajo el nuevo modelo ver Barna (2014)

Este articulo retoma algunos elementos trabajados en una ponencia presentada en la III Reunión Nacional de Investigadoras/es en Juventudes, Argentina, Viedma-Río Negro, octubre de 2012. Agradecemos los co-

Ver proyecto de ley del régimen penal juvenil propuesto por el oficialismo

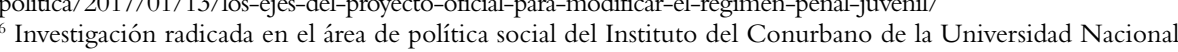
de General Sarmiento.

Los cuestionamientos más importantes de la procuradora a la nueva normativa referirían a la inexistencia de los nuevos organismos y, por ende, que no estaba constituida la nueva autoridad de aplicación ni se contaba con los recursos para ello. El ejecutivo provincial palió varios de los señalamientos y 'vacíos' de la ley a través del decreto reglamentario $(300 / 2005)$.

Esto da cuenta de las resistencias de los actores del poder judicial que percibieron el nuevo marco normativo como una pérdida de poder frente al ejecutivo. Para el análisis de este proceso ver Azcáratey Guemureman (2005). Además de una confrontación entre los poderes judicial y ejecutivo, como destacan las autoras, esta disputa puede ser analizada como parte de la disputa entre duhaldistas y felipistas al interior del PJ bonaeegislatura -la 12067 de diciembre del ano 2000- que no pudo ponerse en funcionamiento por objeciones del procurador general del poder judicial.

'También se creó una comisión interministerial (en procura de dar sustento al principio de co-responsabilidad y al carácter multidimensional de los problemas de vulneración de derechos), asimismo se promovía la creación de consejos locales (Art 22.2, anexo 1, decreto reglamentario 300/05 de la ley 13298).

El art. 63 de la ley 13634 establece. Inimputabilidad por su edad. Comprobada la existencia de un hecho calificado por la Ley como delito, y presumida la intervención de un niño que no haya alcanzado la edad establecida por la legislación nacional para habilitar su punibilidad penal, el Agente Fiscal solicitará al Juez de Garantias su sobreseimiento. Sin perjucicio del cierre del proceso penal respecto del nino, si se advirtiere la existencin de alguna vulneracion de sus derechos especificos, el Juez de Garantias establecerá la pertinencia de aplicar alguna de las Servicio de Proteción de Derechos correspondiente $\gamma$ comuniceń tol decisín a su representante legl o aute su ausenci al Asesor de Incapaces" (el destacado es nuestro). Por su parte el art. 64 expresa: "en casos de extrema gravedad en los que las características del hecho objeto de intervención del sistema penal aconsejen la restricción de libertad ambulatoria, el fiscal podrá requerir al juez de garantías el dictado de una medida restrictiva de libertad ambulatoria.

Si bien estas intervenciones no formaron parte de la propuesta original del Programa Propiciar, recientemente el Servicio Local de la Matanza comenzó a intervenir tal como lo establece esta ley. Más adelante se desarrolla y se hace alguna observación al respecto.

${ }^{12}$ Dado nuestro recorte analítico, no profundizamos aquí el debate en torno al régimen penal juvenil ni sobre las relaciones entre pobreza/exclusión y delito. Al respecto, que hay una abundante bibliografia e investigación
${ }^{13}$ Hacemos uso de los datos oficiales publicados más recientes. Si bien no contamos con información oficial los últimos años.

${ }^{14}$ Según datos del programa, hacia 2009 se recibían más de 330 solicitudes de intervención descendiendo las mismas hasta llegar a 232 en 2016

${ }^{15}$ Según datos del programa, hacia 2009 se recibían más de 330 solicitudes de intervención descendiendo las mismas hasta llegar a 232 en 2016

${ }^{16}$ Según datos del programa, hacia 2009 se recibían más de 330 solicitudes de intervención descendiendo las mismas hasta llegar a 232 en 2016

En las situaciones de jóvenes mayores de 16 años, esta intervención corresponde a la justicia y se canaliza a ${ }_{18}$ Pas de los Centros de Referencia provinciales previstos por la ley. proximidad (Catenazzi y Da Representaçao 2009).

20 El Propiciar cuenta con 15 operadores territoriales, dos psicólogas, una administrativa y una trabajador social quien ocupa el rol de la coordinación. Tal como se señaló en apartado 2, dado lo extenso y heterogéneo del municipio y con el fin de adecuar las características de los dispositivos a las del partido de La Matanza, el territorio es dividido en 3 zonas en función de indicadores socio económicos.

${ }^{22}$ También sucede que en muchas escuelas no existen equipos de orientación escolar con lo que cualquier intento para divulgar nuevos acuerdos y formas de intervención en conjunto se dificultan.

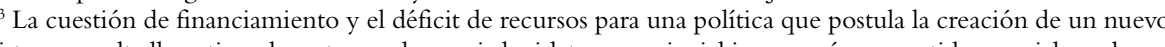
sistema to 2011 pal a monto de cien millones de pesos (Ley de Presupuesto 2012 art. 101:Autorízase al Poder Ejecutivo, dentro de la suma aprobada por los artículos $1^{\circ}$ y $2^{\circ}$ de la presente Ley, a incrementar en la suma de pesos cien millones .... con destino a los Servicios Locales de Protección de Derecho del Niño establecidos en la Ley No ${ }^{\circ} 13.298$ ). ${ }^{24}$ De acuerdo a la ley 13.298 los municipios que deben "Convocar y coordinar los Consejos Locales de Promoción y Protección de los Derechos del Niño para la formulación de un Plan de Accion Local de acuerdo a las competencias definidas por este Decreto" (ley 13.298, decreto reglamentario 300/05, anexo 1, art. 22.2.). Dichos Consejos son espacios multiactorales con representantes de distintos organismos locales que trabajan en relación a politicas de niñez. En el caso del municipio de La Matanza, en mayo de 2007 se llevó acabo la primera reuniớn entre distintos organismos gubernamentales con el objeto de articular las inIntersectorial del Sistema de Promoción y Protección de los Derechos del Niño de La Matanz" constituý Lase para que hacia fines de 2009 se formalice como instancia propia del Consejo Local de Promoción y Protección de los Derechos del Niño de La Matanza.

${ }_{25}^{25}$ Aun en los contextos más hostiles, como en algunos países de Centroamérica donde se consolidaron pandillas juveniles denominadas maras, las políticas de mano dura no sólo demostraron su ineficacia para disminuir el delito sino que potenciaron y recrudecieron la violencia. Ver Cruz y Carranza (2006).

thaceso a la justicia se plantea en al sentido anplo y profindo de la concepción de justicia, desde ya va más allá del sistema de justicia y de la justicia punitiva o penal. 


\section{Referencias}

Abramovich, Víctor y LauraPautassi (2009) "El enfoque de derechos y la institucionalidad de las políticas sociales", en V. Abramovich y L. Pautassi, Laura (comps.) La revisión judicial de las políticas sociales. Estudio de casos, Buenos Aires, Editores del Puerto, pág. 279-340.

Azcárate, Julieta ySilviaGuemureman (2005) "Informe sobre la cuestión Legislativa en Provincia de Buenos Aires: Crónica de una historia que se repite", Observatorio Adolescentes y Jóvenes IGG-UBA.

Barna, Agustín (2014) "Clasificaciones y estimaciones en la gestión de la infancia "con derechos vulnerados». Prácticas cotidianas de intervención en un dispositivo estatal del conurbano bonaerense”. Antropolítica 36: pag. 113-148.

Beloff, Mary (1999) "Modelo de la protección integral de los derechos del niño y de la situación irregular: un modelo para armar y otro para desarmar", en Justicia y Derechos del Niño, UNICEF-Ministerio de Justicia, Buenos Aires. Pag. 9-22.

Carman, M. Vieira, y Ramiro Segura (2013) Segregación y diferencia en la ciudad. Quito: FLACSO-CLACSO.

Catenazzi, Andrea y Da Representaçao, Natalia (2009) "Acerca de la gestión de la proximidad", en Magdalena Chiara y Mercedes Di Virgilio, (comps.) Gestión de la politica social: conceptos y herramientas, UNGS/Prometeo, Buenos Aires. pág. 119-136.

Cruz, José y Carranza, Marlon (2006) "Pandillas y políticas públicas: el caso de El Salvador", en Javier Moro (ed.) Juventudes, violencia y exclusión. Desafíos para las políticas públicas, INDES-INAP-Magna Terra, Guatemala. pág. 133-176.

Daroqui, A. López, A.L y Cipriano García, R., coords. (2012) Sujetos de castigo, Hacia una sociología de la penalidad juvenil, Editorial Homo Sapiens, Rosario.

Fassin, Didier (2016) La fuerza del orden. Una etnografía del accionar policial en las periferias urbanas, Ed. Siglo XXI, Buenos Aires.

Gomes da Costa, Antonio (1995) Pedagogía de la presencia, Ed. Losada, Buenos Aires.

Guemureman, Silvia (2015) (dir.) Políticas penales y de seguridad dirigidas hacia adolescentes y jóvenes, Ed. Rubinzal, Buenos Aires.
Lipsky, Michael (1971) "Street-Level Bureacracy and the Analysis of Urban Reform", Urban Affairs Quarterly, 6 (4) 391-409.

Pilotti, Francisco (2001) Globalización y Convención sobre los Derechos del Niño: El contexto del texto. Santiago de Chile: CEPAL, Serie Políticas Sociales Nro. 48.

Reguillo, Rossana (2004) Emergencia de culturas juveniles. Estrategias del desencanto, Ed. Norma, Bogotá.

Rossi, Julieta y Moro, Javier (2014) Ganar derechos. Lineamientos para la formulación de políticas públicas basadas en derechos, IPPDH-MERCOSUR.

Salgado,Vanesa (2015) “La construcción mediática de la minoridad.Tratamiento de los delitos cometidos por jóvenes y construcción de la díada seguridad/inseguridad, en Guemureman, Silvia (dir.) Politicas penales y de seguridad dirigidas hacia adolescentes y jóvenes, Ed. Rubinzal, Buenos Aires, pág. 551-588.

Saraví, Gonzalo (2006) "Los eslabones de la violencia juvenil: acumulación de desventajas en la transición a la adultez", en JavierMoro, ed., Juventudes, violencia y exclusión desafíos para las políticas públicas, INDES-INAP-Magna Terra Ed., Guatemala, pág. 33-46.

Secretaría de Ciencia,Tecnología y Políticas Educativas (2012) Encuesta de Condiciones deVida de La matanza del año 2012, Municipalidad de La Matanza, Provincia de Buenos Aires.

Tonkonoff, Sergio (2007) "Juventud, exclusión y delito. Notas para la reconstrucción de un problema". Alegatos 65:33-46.

Villalta, Carla (2004) "Una filantrópica posición social: los jueces en la justicia de menores” en Sofia Tiscornia, comp., Burocracias y violencias. Estudios de antropología jurídica. Buenos Aires: Facultad de Filosofia y Letras de la Universidad de Buenos Aires, pág. 281-326.

Vitale, Gabriel y Abalos, Cecilia (2007) "Ley 13634. Consideraciones sobre los nuevos fueros de familia y responsabilidad penal juvenil en la Provincia de Buenos Aires. Un avance hacia el Estado de Derecho y justicia" Revista Rap digital Provincia de Buenos Aires. Actualidad jurídica provincial y municipal bonaerense, año IV, $\mathrm{N}^{\circ} 48$.

Zaffaroni, Eugenio (2004) La cuestión criminal, Ed. Planeta, Buenos Aires.

Cómo citar este artículo:

Moro, Javier y Orizaola Guillermo (2017) “Adolescentes con episodios conflictivos con la ley penal: restituir derechos y constituir ciudadanía. Reflexiones a partir del Program Propiciar, de La Matanza". Revista Perspectivas de Políticas Públicas vol. 6 № 12:305-331. 